\title{
Rebuttal of comments by Griffiths, Lader and Greenblatt to Review by Woods and Winger
}

Dr Griffiths curiously reiterates points we have made repeatedly and implies that we have failed to make them. Our first review on benzodiazepines (Woods et al. 1987) noted that, in terms of the volume of drugs dispensed, most use is by chronic users; but we consider it more important to count people rather than pills, and we stand by our point that most actual use of benzodiazepines is appropriate. Also, we have emphasized the need for study of the effects of long-term use in each of our publications about benzodiazepines (Woods et al. 1987, 1988, 1992), including our article in this issue.

It does a great disservice to chronic users of prescribed benzodiazepines to label them as drug addicts. The vast majority of users are following their physicians' orders. Benzodiazepine users tend to decrease use over time (Woods et al. 1987); this too differs from, e.g., chronic daily nicotine use, which typically results from many years of increasing use (Shiffman 1989; DHHS 1991). Benzodiazepine users also differ from addicts in that, after discontinuing use, they are unlikely to think about or wish to resume taking the drugs (Lucki et al. 1991).

In this issue and previously (Woods et al. 1987, 1988, 1992), we have considered the evidence for and implications of the preference for benzodiazepines among polydrug abusers. But we do not agree with Drs. Griffiths or Lader that this is "the important point" or that it reflects "a high abuse potential" in any acceptable use of the term; we believe the relatively important point is that most patients with anxiety or insomnia are not at risk of abusing benzodiazepines.

Dr. Lader makes several very specific points for which he offers little substantiation. He notes "increas-

J. Woods $(\varangle) \cdot G$. Winger

Department of Pharmacology, University of Michigan Medical

School, 6322 Medical Science Building, Ann Arbor,

MI 48109-0626, USA ing evidence" that "non-drug treatments are at least as effective" as and safer than benzodiazepines for mild anxiety or insomnia, but cites only a single, 10 -yearold reference. We doubt that current, non-drug treatment is a practical alternative for even the majority of patients. Dr. Lader offers no references for his assertion that "severely anxious patients and those with panic attacks respond better to antidepressants". Most of the relevant studies of panic disorder have compared alprazolam with imipramine, and have found the drugs equivalent in effectiveness (Hollister et al. 1993; Rosenberg 1993).

We know of no-one besides Dr. Lader who would suggest that, by referring to "physiological" dependence, we meant to imply "some element of normality". He emphasizes that benzodiazepine withdrawal can be intolerable, but takes issue with our point that discontinuation by tapering the dose can minimize this discomfort. For support, he cites Schweitzer et al. (1990), who, however, made exactly our point, and who found that withdrawal reactions following gradual taper were "rarely more than mild to moderate" (Schweitzer et al. 1990).

Dr. Greenblatt suggests correctly that, from a scientific perspective, we are guilty of oversimplification in choosing to refer to the duration of action of drugs as if this were equivalent to half-life. For many researchers as well as clinicians, the options for changing effect with a particular benzodiazepine are limited to manipulating dose and/or frequency of administration. Information about the pharmacokinetic parameters described by Dr. Greenblatt would surely improve many of our judgements; regrettably, this level of sophistication remains beyond the vast majority of us.

\section{References}

Department of Health and Human Services (1991) Second Triennial Report to Congress from the Department of Health and Human 
Services on Drug Abuse and Drug Abuse Research. DHHS Publication No. (ADM)91-1704. Government Printing Office, Washington DC

Hollister LE, Muller-Oerlinghausen B, Rickels K, Shader RI (1993) Clinical uses of benzodiazepines. Clin Psychopharmacol 13[suppl. 1]:1S-169S

Lucki I, Volpicelli JR, Schweizer E (1991) Differential craving between abstinent alcohol-dependent subjects and therapeutic users of benzodiazepines. NIDA Res Monogr 105:322-323

Rosenberg R (1993) Drug treatment of panic disorder. Pharmacol Toxicol 72:344-353
Schweitzer E, Rickels K, Case G, Greenblatt DJ (1990) Long-term use of benzodiazepines: II. Effects of gradual taper. Arch Gen Psychiatry 47: 908-915

Shiffman SM (1989) Tobacco "chippers"- individual differences in tobacco dependence. Psychopharmacology 97:539-547

Woods JH, Katz JL, Winger G (1987) Abuse liability of benzodiazepines. Pharmacol Rev 39:251-413

Woods JH, Katz JL, Winger G (1988) Use and abuse of benzodiazepines: issues relevant to prescribing. JAMA 26:3476-3480

Woods JH, Katz JL, Winger G (1992) Benzodiazepines: use, abuse and consequences. Pharmacol Rev 44:151-347 